Running head: EMOTION AND BIBLE TRANSLATIONS

Differences in the Emotional Content in Different Bible Translations

Robert G. Franklin, Jr. \& Channing L. Crisler

Anderson University

Contact information:

Corresponding Author

Robert G. Franklin, Jr.

Anderson University

316 Boulevard

Anderson SC 29621

Email: rfranklin@andersonuniversity.edu 


\begin{abstract}
The Christian Holy Bible is the most translated document of all time. In this study, we used sentiment analysis to investigate whether common English translations varied in their emotionality, comparing how positive or negative they were. We predicted that more dynamic translations, which are not as constrained to the literal meaning of the text would have a more positive emotional sentiment than more formal translations, which are more focused on accurately conveying the literal meanings of individual words and syntax. More dynamic translations, including The Message and the New Living Translation were more emotionally positive and less negative than translations which mix formal and dynamic approaches. More formal translations, such as the New American Standard Bible and the English Standard Version, were significantly more negative. These findings illustrate that translations significantly vary in emotionality and indicate the importance of using many different translations to accurately assess the original meaning.
\end{abstract}

Keywords: The Bible; Emotional Valence; Sentiment Analysis; Bible Translation 


\section{Differences in the Emotional Content in Different Bible Translations}

The emotional content that is present within a narrative plays an important role in the comprehension of a narrative (Miall, 1989). Any document, story, or literary narrative that contains human characters has an emotional component, reflected by the emotions of the characters themselves, the empathy a reader has for characters, and the emotions a text elicits in the readers. When we perceive others, we naturally attempt to understand what the characters are thinking and feeling and empathize with those individuals through a set of neural mechanisms specifically disposed for this purpose (Franklin et al., 2013). This emotional content affects how stories are understood and processed, as readers are able to accurately understand the emotions present in text, and do this as a process of reading (Gernsbacher, Goldsmith, \& Robertson, 1992, Vega, 1996). Reading stories with positive or negative affect also can induce different emotional states in readers as well (e.g., King, Hicks, Krull \& Del Gaiso, 2006).

Because of the importance of emotional content on reading text, we wanted to investigate how emotional content may be different in different translations of the Christian Holy Bible. The Bible is the most widely-read and most translated literary corpus of all time, and exists in English in a variety of translations. Though these translations are all attempting to reproduce original source documents, they vary in their approaches. However, it is unclear whether they vary in their emotional valence, and whether some translations are consistently more positive, or more negative, and whether translations vary in their overall emotionality, having more positive and negative affect. Given that the emotional content of a text plays an important role in how text is understood and different individuals use different English versions of The Bible as a guide to their own religious and spiritual life, measuring the emotional valence of various translations may play an important question in understanding the effects of emotion on one's religious life. 


\section{Translating the Bible}

The Christian Holy Bible is the most translated document of all time. Given that the Bible is made up of text from many manuscripts from many eras, has at least three reference languages (Hebrew, Aramaic, and Greek), and is so widely and frequently translated, it represents perhaps the best example of the issues involving translation, especially translation of historical documents. In attempting to translate the Bible, translators have to try to convey meaning through analyzing lexemes, individual words or groups of words which have a single symbolic meaning, syntax, and idioms.

Bible translations vary on how literal they are. A formal translation attempts to translate the words and structures of an original language into a designated receptor language specifically focusing on the original individual words, lexeme, and syntax (Blomberg, 2010). This approach may be more accurate for translating the original lexeme, idiom, and syntax but one drawback of this approach is that it may eclipse the original and broader meaning of a passage. For instance, passages may contain metaphors or other figures of speech which were clear to readers of one language that are confusing or even misleading when translated literally. In addition, certain terms may be appropriate in one language, but when translated literally become insulting or offensive in a different language.

A different approach is using dynamic translations, which attempt to capture the thought of the original passage but are not as constrained by woodenly translating the exact meaning of each word. In this translation approach, the translators alter the direct translation of specific words in order to capture the larger meaning of a passage. The advantage of this approach is that it strives to duplicate the original function of a passage, but it does not attempt a word for word equivalent of the original language at every turn. This approach allows translators to address 
some of the problems with literal translations and adapt language to a modern audience but has the downside of being more subjective. Given there is no way to know the original author's intent, it is possible that the interpretation may be incorrect or add errors to the text.

Of the formal translations, the King James Version (KJV) is the most widespread and famous English Bible translation, originally completed in 1611 and later revised in 1982. Though very comprehensive for its time, other literal translations have been developed from the $19^{\text {th }}$ century until today. These translations have attempted to update the KJV in a number of ways including the use of contemporary English and, especially with respect to the New Testament, the use of more ancient and diverse source manuscripts. Examples of more literal versions include the New American Standard Bible (NASB) and the English Standard Version (ESV).

In contrast to the literal translations, some modern translations in the $20^{\text {th }}$ century have used a more dynamic approach. These include the Good News Bible, (GNT), New Living Translation (NLT) and The Message.

The NLT and The Message are unique because they are categorized as paraphrases, or fully functional equivalent translations, which tend to target audiences whose English comprehension or literacy skills are low (Blomberg, 2010). This may include using more familiar terms and simpler grammatical structures. Paraphrases attempt to capture the message of the text, and in many ways may be more understandable than a literal translation which may use idioms and examples which were familiar to ancient writers but whose meaning may be lost in translation. However, these paraphrases are inherently more subjective and thus may be more vulnerable to bias.

\section{Emotion and Translation}


One issue with dynamic translation and paraphrasing is that it might alter the emotional character of an original text. When retelling autobiographical memories, participants frequently increase and exaggerate the emotional character of their stories when they are told to focus on the emotions of the situations (Beike \& Wirth-Beaumont, 2005; Marsh, 2007). Though translation is not the same as autobiographical memory by any means, it is possible these same biases may be present, especially when translators are attempting to focus on the emotional content of a translation in addition to the literal meaning of a translation.

There are several examples where different translations may alter the emotional content. One possibility is that dynamic translations may alter stories to make them less violent or repulsive. One notable example is a passage in the book of Judges describing the stabbing of Eglon, the king of Moab by Ehud the Israelite. Judges 3:22 describes the stabbing in vivid detail, describing how Eglon's fat closed over and covered the sword after he was stabbed. The passage ends with a description of the result of this stabbing, ending with the use of the Hebrew word which can literally mean "the feces came out" (Brown, Driver, \& Briggs, 2013; Koehler \& Baumgartner, 2001). Several different translations render the term in different ways. Formal translations refer to this part in many ways, with the KJV asserting "the dirt came out" and the NASB notes that "and the refuse came out". Notably, this part is omitted from several dynamic translations, such as the GNB and The Message.

The reason this example in Judges is notable is that part of the theme of this book is to use vivid and graphic details of violence to show the consequences of the sins of Israel (Butler, 2009; Dumbrell, 2002). Though details like the one discussed above may not be directly necessary for the story being told, they play an important role in the theme that is conveyed by the author. 
The question of interest we had in this study was to compare the emotional valence of formal versus dynamic translations of the Bible. Dynamic translations inherently have more subjectivity where translators try to use their views on what the meaning of the passage is in order to better inform the translation. This increased subjectivity may lead, these translations to have character than formal translations. Specifically, we reasoned they may be more emotional and more positive than formal or literal translations.

Secondly, we investigated whether other translation goals may affect the emotional valence of a translation. The New International Reader's Version (NIRV) is a translation designed to be more readable than other translations, attempting to simplify language to make it more readable, especially for children. (Blomberg, 2010). Insofar that this translation is designed for children, it is possible that it may contain a different emotional character than other translations, specifically by omitting details which may be objectionable for children. For example, Judges 3:22 in the NIV states "Even the handle sank in after the blade, and his bowels discharged. Ehud did not pull the sword out, and the fat closed in over it." The NIRV is almost identical, but omits the passage about the bowels discharging, stating: "Even the handle sank in after the blade. Eglon sagged and fell to the floor. Ehud didn't pull out the sword. And the fat closed over it."

In order to assess the emotional valence of translations, we used sentiment analysis through natural language processing. Sentiment analysis is a technique using computer algorithms to judge subjective characteristics of a body of text. In this case, we assessed the emotional valence of a passage. Sentiment analysis is an effective way of objectively quantifying emotional character since it does not have any human inputs and may not be biased by larger meanings of a passage or the theological implications of a passage. Though there is variation 
among how various sentiment analysis algorithms work, most of these methods generally use the following process: human raters rate the emotional valence of words, rating specific terms as to how positive or negative those terms are. Then these ratings are used as the basis of an algorithm which calculates the number of those terms within a source text in order to assess the amount of positivity or negativity within a body of text.

Sentiment analysis has been used to examine the emotional character of many online sources, such as tweets (e.g. Agarwal, Xie, Vovsha, Rambow, \& Passonneau, 2011; O'Connor, Balasubramanyan, Routledge, \& Smith, 2010) and online product reviews (e.g. (McGlohon, Glance \&Reiter, 2010). Researchers have also used it to investigate the emotional character and plot trajectory of works of fiction (e.g., Jockers, 2015). However, no work to our knowledge has used sentiment analysis to examine different Biblical translations.

\section{Method}

\section{Source Materials}

We examined formal and dynamic English translations. The formal translations used were the New American Standard Bible (NASB), the English Standard Version (ESV), the King James Version (KJV), the New King James Version (NKJV), and New Revised Standard Version, Catholic Edition (NRSV-CE). The dynamic translations used were the Good News Translation (GNT), the New Living Translation (NLT), and The Message (Message). In addition, we investigated the New International Version (NIV) and Holman Christian Standard Bible (HCSB) which are described as hybrid of formal and dynamic translations (Blomberg, 2010).

With the exception of the KJV, we limited our analysis to translations published after 1950. The KJV was included due to its common use today and its historical value, but we believed that it may not be as accurately measured by sentiment analysis. This is because all the 
sentiment analysis techniques used are based on texts using modern English spellings and many spellings in the KJV are not used in contemporary language. However we included it in our analysis, given these caveats.

\section{Sentiment analysis}

We used the NRC word association lexicon (EmoLex: Mohammad \& Turney, 2010) as implemented through the syuzhet package (version 1.0.0) in $\mathrm{R}$ in order to assess emotional valence (Jockers, 2015). The NRC word association is a crowd-sourced dictionary of 14,182 terms where raters rated the positivity and negativity of each term. The sentiment analysis package used counts the presence of terms that are associated with positive valence and negative valence. A list of terms and their word-sentiment associations are available at http://saifmohammad.com/WebPages/NRC-Emotion-Lexicon.htm. The EmoLex sentiment gave two output values for text, a number reflecting the number of positive words in a passage and a number reflecting the number of negative words in a passage.

As a second measure of sentiment, we used the Syuzhet sentiment analysis package developed by Jockers (2016). This measure of sentiment was developed using a custom sentiment dictionary developed in the Nebraska Literary Lab at the University of Nebraska. This method used 165,000 human coded sentences taken from several current models in order to create a better measure of sentiment tuned for narrative writing, as opposed to other models tuned for measuring opinion in online writing, such as product reviews and tweets. The Syuzhet sentiment package gave a single number for each item of text reflecting the relative sentiment of the passage, with zero indicating a neutral sentiment, positive numbers reflecting positive sentiment and negative numbers reflecting negative sentiment.

\section{Method}


We measured sentiment by using each chapter of each of the books of the Bible as a separate passage. We entered each chapter into $\mathrm{R}$ as a single corpus of text and examined the sentiment for each chapter. This was done separately for each translation. We only examined the 66 books considered canonical by most Protestant denominations because they were available in all translations. These analyses gave us three values for each chapter (e.g. Genesis 1), the positive sentiment measured by the EmoLex, the negative sentiment measured by the EmoLex, and the sentiment measured by the Syuzhet method.

In addition, we calculated two more values based on these methods. We calculated a value for emotionality by using the sum of positive and negative emotion values from the EmoLex. This was done to assess the total amount of emotional content, both positive and negative, in the passage. This was done because a translation could use more positive words and more negative words than a different version, and thus have more emotional words in general. Further, we calculated a valence measure by calculating the difference between the positive and negative ratings from the EmoLex. This measure was designed in order to capture the overall valence of a translation by comparing positivity to negativity.

\section{Results}

\section{Overview of Results}

We used linear mixed effects modeling to assess differences between translations and also investigated differences between the Old Testament (OT) and New Testament (NT), along with interactions between translation and testament. Translation was entered as a categorical factor into each model, with the NIV used as the baseline translation because it combined dynamic and formal translational methods. Thus, all coefficients reported below are relative to the sentiment present in the NIV. Testament was entered as a categorical factor with the OT used 
as the baseline level. Book and chapter were entered as categorical random effects into the model.

In the results below, we examine positivity, negativity, emotionality (positivity plus negativity), and valence (positivity minus negativity). Table 1 shows as summary of our findings combining the results from all the models, indicating if a translation was higher or lower than the NIV in a specific model

\section{Positivity}

Linear mixed effects models showed a clear trend supporting the hypothesis that more formal translations were more negative compared to the NIV and more dynamic translations were more positive (see Table 2). Compared to the NIV, the more literal translations of the ESV, KJV, and NRSV-CE were less positive than the NIV. The moral dynamic translations were more positive, with the NLT and MSG being significantly more positive than the NIV (see Figure 1). Surprisingly, the NIRV was less positive than the NIV, which was contrary to our hypothesis.

Testament also played a role in sentiment. The OT was less positive than the NT overall. Whereas most translations did not show a significant interaction between testament and positivity, there was a significant interaction between testament and positivity for the MSG. Based on inspection of the means, the OT in the MSG was relatively the same level of positivity as the OT in the NIV, but the NT in the MSG was significantly more positive than the NT in the NIV.

\section{Negativity}

Negativity showed a different set of patterns than positivity (see Figure 2). Linear mixed models revealed that the KJV and NKJV were significantly less negative than the NIV baseline (see Table 3). For the KJV, this may reflect limitations of the sentiment analysis looking at 
manuscripts not using modern English spellings, since the KJV was lower in positivity as well. However, the pattern showing the NKJV as less negative than the NIV would not reflect this limitation. The NIRV was also significantly less negative than the NIV, possibly due to its being targeted for children. Notably, however, the dynamic translations were not less negative than the NIV or most of the more formal translations. The NASB was the only translation significantly more negative than the others.

When examining testament, there were no differences in negativity between the OT and NT. The only interaction between testament and translation was the ESV, which showed a larger difference in negativity between the OT and the NT than the NIV baseline.

\section{Emotionality}

Emotionality, or the combination of positivity and negativity, revealed an interesting pattern (see Figure 3). When compared to the NIV, the KJV, the NKJV, and the NIRV were significantly less emotional (see Table 4). As noted before, this may be a methodological limitation for the KJV. However, this would not be the case for the NKJV. Also, rather than showing a clear bias toward being more positive, the NIRV was less emotional than the baseline text, likely due to a decrease in negativity. This shows that the translation of the NIRV may reduce the negativity of the text, relative to the other translations, possibly due to addressing the target audience of children.

The Message and the NLT were significantly more emotional than the baseline translations, indicating that dynamic translations may have additional emotional character than more formal translations.

\section{Valence}


When examining valence, it is clear that more dynamic translations have a more positive valence, with the NLT and Message being much more positive in valence than the NIV (see Figure 4 and Table 5). Of the more formal translations, only the ESV had significantly more negative valence than the comparison baseline, whereas the more formal translations and the translations that attempted to combine a formal and a dynamic approach had a similar valence.

There were differences in valence between the OT and NT, with the OT being more negative in valence than the NT. This is likely due to more positivity in the NT, as noted above. In addition, there was an interaction between testament and the Message, which reflects the stronger difference in positivity between the testaments in the Message (see the positivity analysis above).

\section{Discussion}

We examined whether different Biblical translations had differences in their emotional content, specifically examining positivity, negativity, overall emotionality, and the emotional valence of the manuscripts. We hypothesized that more dynamic translations may be more positive and less negative than more literal translations. In addition, we predicted that the NIRV, a translation designed for children, may be more positive and less negative as well, due to the specific translation goals.

These results showed that more dynamic translations were more positive than more formal translations and translations that combined dynamic and formal approaches. The Message and NLT were more positive and had a higher overall valence (positivity minus negativity), when compared to the other translations. The lack of differences in negativity suggests that these findings are due to enhanced positivity in these translations, relative to the other translations, rather than reduced negativity. 
The findings were not as clear for translations which mix literal and dynamic methods and those who use primarily formal methods. Of those which mix dynamic and literal methods, the HCSB was very similar to the NIV emotionally when compared to translations which mixed formal and dynamic methods. The ESV, which strives to steer a via media, or middle path between literal and dynamic methods (Blomberg, 2010), was significantly less positive and had significantly more negative overall valence. The NASB, one of the most literal translations, was significantly more negative but did not have a significantly different valence than the NIV. This suggests the more formal translations are less positive and more negative than the baseline translation.

The NIRV was significantly less negative than the NIV, but did not differ in positivity. Given these differences were present only for negativity, this suggests that the translators may have reduced the negativity present in this translation due to the target audience. How this was done may not be clear, but it may reflect an attempt to use less negative words to convey the same messages.

Finally, the KJV and NKJV had overall less emotional content than the other translations. This may reflect limitations of the method, specifically with the KJV, but the finding that this pattern persisted in the NKJV suggests this translation has less emotionality than the other Biblical translations.

\section{Limitations and Future Directions}

These findings show that the emotional content differs in different English translations of the Bible. However, some limitations exist. One limitation is the use of the sentiment analysis method itself. Given it looks for the frequency of emotional words, it may not accurately convey the larger emotional sentiment of a passage, especially if the emotional content is communicated 
through complex grammatical structures that are not easily parsed in single words. For instance, a very positive or very negative concept can be conveyed with relatively neutral words.

However, the use of large bodies of text should help reduce the impact of these situations, since the metrics used here are the average of many different verses.

A second limitation to these findings is that we cannot conclusively state why translations vary in their emotional sentiment. Although the data fit our general hypothesis that literal translations are less positive than dynamic translations, these data do not fully fit these hypotheses and other variation exists in translations. Specifically, the theological goals of different translations may affect the emotional sentiment of different translations.

One notable caveat which must be addressed is that these findings do not ipso facto describe the accuracy of the translations. Without the ability to assess the emotional content of the source materials, it is impossible to suggest that translations are more or less accurate based solely on these findings. It may be the case that the more dynamic translations are capturing more positivity which is present in the source materials that is lost when using a more formal translation. Conversely, it may be that the increased bias possible in more dynamic translations may lead to a more positive bias in the translation.

This leads to one of the most important applications of these findings, which is that multiple translations should be used to examine the emotional content of passages. Given the importance of the Bible as source material for Christian theology as well as the Christian religious experience, the use of several translation approaches may be the best way to capture the emotional content of the passage.

Further, the use of only one translation may lead to differences in the emotional experience of Christianity. For instance, the use of only one translation which is very positive 
may lead to a different emotional experience than if a person uses only one translation which is very negative. This may also lead to a selection bias where people who have a general tendency to more positive experiences may choose more positive translations and those who have a general tendency to more negative experiences may choose more negative translations. This is a hypothesis for future research.

Though these findings do have limitations, they still show that emotional character does vary as a function of translation. This indicates that theologians and translators should be aware of the emotional content of their translation and the possibility this may vary in different translations. Readers also should be aware of these differences as well and note that the most accurate approach may be to use several translations to attempt to examine the emotional character of a passage. 


\section{References}

Agarwal, A., Xie, B., Vovsha, I., Rambow, O., \& Passonneau, R. (2011, June). Sentiment analysis of twitter data. In Proceedings of the workshop on languages in social media (pp. 30-38). Association for Computational Linguistics.

Beike, D., \& Wirth-Beaumont, E. (2005). Psychological closure as a memory phenomenon. Memory, 13, 574-593.

Blomberg, C. L. (2010). A Handbook of New Testament Exegesis. Baker.

Brown, F. (2003). The Brown-Driver-Briggs Hebrew and English Lexicon. Hendrickson.

Butler, T. C. (2009). Word Biblical Commentary on Judges. Thomas Nelson.

Dumbrell, W. J. (2002). The Faith of Israel: A Theological Survey of the Old Testament. Baker.

Franklin, R.G., Jr., Nelson, A. J., Baker, M., Beeney, J. E., Lenz-Watson, A., Vescio, T. K., \& Adams, R. B. Jr. (2013). Neural mechanisms of empathy for humans and animals. Social Neuroscience. 8, 217-227.

Gernsbacher, M. A., Goldsmith, H. H., \& Robertson, R. R. (1992). Do readers mentally represent characters' emotional states? Cognition \& Emotion, 6, 89-111.

Jockers M. L. (2015). Syuzhet: Extract Sentiment and Plot Arcs from Text. https://github.com/mjockers/syuzhet.

Jockers, M. L., (2016). More Syuzhet validation. http://www.matthewjockers.net/2016/08/11/more-syuzhet-validation/. Accessed September 14, 2016. 
King, L. A., Hicks, J. A., Krull, J. L., \& Del Gaiso, A. K. (2006). Positive affect and the experience of meaning in life. Journal of Personality and Social Psychology, 90, 179196.

Koehler, L. \& Baumgartner, W. (2001). The Hebrew and Aramaic Lexicon of the Old Testament, 2 Vols. Brill.

Marsh, E. J. (2007). Retelling is not the same as recalling implications for memory. Current Directions in Psychological Science, 16, 16-20.

Miall, D. S. (1989). Beyond the schema given: Affective comprehension of literary narratives. Cognition \& Emotion, 3(1), 55-78.

McGlohon, M., Glance, N, \& Reiter, Z. (2010). Star quality: Aggregating reviews to rank products and merchants. In Proceedings of the International Conference on Weblogs and Social Media (ICWSM- 2010).

Mohammad, S. \& Turney, P. (2010). Emotions evoked by common words and phrases: Using Mechanical Turk to create an emotion lexicon." In Proceedings of the NAACL-HLT 2010 Workshop on Computational Approaches to Analysis and Generation of Emotion in Text, LA, California.

Nida, E. A. (1964). Toward a science of translating: with special reference to principles and procedures involved in Bible translating. Brill Archive.

O'Connor, B., Balasubramanyan, R., Routledge, B. R., \& Smith, N. A. (2010). From tweets to polls: Linking text sentiment to public opinion time series. ICWSM, 11(122-129), 1-2.

Vega, M. (1996). The representation of changing emotions in reading comprehension. Cognition \& Emotion, 10(3), 303-322. 
Table 1. Summary of mixed linear models showing differences in emotional sentiment compared to the baseline NIV translation.

\begin{tabular}{lllll} 
Translation & Positivity & Negativity & Emotionality & Valence \\
\hline NASB & same & more & same & neutral \\
ESV & less & same & same & negative \\
KJV & less & less & less & neutral \\
NKJV & same & less & more & same \\
HCSB & same & same & same & neutral \\
NRSV-CE & less & same & same & same \\
GNT & same & same & same & neutral \\
NIRV & less & less & less & positive \\
NLT & more & same & same & positive \\
The Message & more & same & more & positive \\
\hline
\end{tabular}


Table 2. Linear mixed models investigating differences in positivity in different Biblical translations

\begin{tabular}{|c|c|c|c|}
\hline Factor & $\mathrm{B}$ & SE & $\mathbf{t}$ \\
\hline Intercept (NIV and OT Baseline) & 29.98 & 1.22 & 24.56 \\
\hline NASB & 0.54 & 0.62 & 0.87 \\
\hline ESV & -1.38 & 0.62 & -2.23 \\
\hline KJV & -3.46 & 0.62 & -5.60 \\
\hline NKJV & -1.09 & 0.62 & -1.76 \\
\hline HCSB & 0.75 & 0.62 & 1.22 \\
\hline NRSV-CE & -1.28 & 0.62 & -2.07 \\
\hline GNT & -0.49 & 0.62 & -0.79 \\
\hline NIRV & -1.34 & 0.62 & -2.16 \\
\hline NLT & 3.35 & 0.62 & 5.41 \\
\hline Message & 3.63 & 0.62 & 5.87 \\
\hline Testament (OT baseline) & -8.05 & 1.25 & -6.43 \\
\hline NASB*Testament & -1.11 & 0.70 & -1.58 \\
\hline ESV*Testament & -0.52 & 0.70 & -0.74 \\
\hline KJV*Testament & 0.37 & 0.70 & 0.53 \\
\hline NKJV*Testament & -0.70 & 0.70 & -1.00 \\
\hline HCSB*Testament & -0.77 & 0.70 & -1.10 \\
\hline NRSV-CE*Testament & -0.25 & 0.70 & -0.36 \\
\hline GNT $^{*}$ Testament & 0.77 & 0.70 & 1.09 \\
\hline NIRV*Testament & 1.21 & 0.70 & 1.72 \\
\hline NLT*Testament & -1.20 & 0.70 & -1.71 \\
\hline Message*Testament & -2.99 & 0.70 & -4.24 \\
\hline Random Effects & Variance & $\mathrm{SD}$ & \\
\hline Chapter & 67.2 & 8.197 & \\
\hline Book & 20.49 & 4.527 & \\
\hline Residual & 52.15 & 7.221 & \\
\hline
\end{tabular}


Table 3. Linear mixed models investigating differences in positivity in different Biblical translations

\begin{tabular}{lrrr} 
Factor & $\mathrm{B}$ & $\mathrm{SE}$ & $\mathbf{t}$ \\
\hline Intercept (NIV and OT Baseline) & 16.81 & 1.42 & $\mathbf{1 1 . 8 1}$ \\
NASB & 1.74 & 0.63 & $\mathbf{2 . 7 5}$ \\
ESV & 0.94 & 0.63 & 1.49 \\
KJV & -3.52 & 0.63 & $\mathbf{- 5 . 5 8}$ \\
NKJV & -1.55 & 0.63 & $\mathbf{- 2 . 4 5}$ \\
HCSB & 0.66 & 0.63 & 1.05 \\
NRSV-CE & -0.14 & 0.63 & -0.22 \\
GNT & 0.07 & 0.63 & 0.11 \\
NIRV & -3.37 & 0.63 & $\mathbf{- 5 . 3 3}$ \\
NLT & 0.64 & 0.63 & 1.01 \\
Message & -0.26 & 0.63 & -0.41 \\
Testament (OT baseline) & 0.43 & 1.59 & 0.27 \\
NASB*Testament & -1.25 & 0.72 & -1.74 \\
ESV*Testament & -1.46 & 0.72 & $\mathbf{- 2 . 0 3}$ \\
KJV*Testament & -0.16 & 0.72 & -0.22 \\
NKJV*Testament & -0.62 & 0.72 & -0.87 \\
HCSB*Testament & -0.65 & 0.72 & -0.91 \\
NRSV-CE*Testament & -0.86 & 0.72 & -1.19 \\
GNT*Testament & 0.21 & 0.72 & 0.29 \\
NIRV*Testament & 0.27 & 0.72 & 0.38 \\
NLT*Testament & -0.19 & 0.72 & -0.26 \\
Message*Testament & -0.82 & 0.72 & -1.15 \\
\hline
\end{tabular}

\begin{tabular}{lrr} 
Random Effects & Variance & SD \\
\hline Chapter & 61.99 & 7.87 \\
Book & 35.56 & 5.96 \\
Residual & 54.43 & 7.38 \\
\hline
\end{tabular}


Table 4. Linear mixed models investigating differences in positivity in different Biblical translations

\begin{tabular}{|c|c|c|c|}
\hline Factor & $\mathrm{B}$ & SE & $\mathbf{t}$ \\
\hline Intercept (NIV and OT Baseline) & 46.83 & 2.36 & 19.88 \\
\hline NASB & 2.20 & 1.11 & 1.99 \\
\hline ESV & -0.51 & 1.11 & -0.46 \\
\hline KJV & -7.06 & 1.11 & -6.37 \\
\hline NKJV & -2.72 & 1.11 & -2.45 \\
\hline HCSB & 1.34 & 1.11 & 1.21 \\
\hline NRSV-CE & -1.49 & 1.11 & -1.34 \\
\hline GNT & -0.50 & 1.11 & -0.45 \\
\hline NIRV & -4.78 & 1.11 & -4.31 \\
\hline NLT & 3.92 & 1.11 & 3.53 \\
\hline Message & 3.30 & 1.11 & 2.98 \\
\hline Testament (OT baseline) & -7.69 & 2.48 & -3.11 \\
\hline NASB*Testament & -2.28 & 1.25 & -1.82 \\
\hline ESV*Testament & -1.91 & 1.25 & -1.52 \\
\hline KJV*Testament & 0.29 & 1.25 & 0.23 \\
\hline NKJV*Testament & -1.25 & 1.25 & -1.00 \\
\hline HCSB*Testament & -1.35 & 1.25 & -1.08 \\
\hline NRSV-CE*Testament & -1.04 & 1.25 & -0.83 \\
\hline GNT*Testament & 1.05 & 1.25 & 0.84 \\
\hline NIRV*Testament & 1.55 & 1.25 & 1.24 \\
\hline NLT*Testament & -1.31 & 1.25 & -1.05 \\
\hline Message*Testament & -3.74 & 1.25 & -2.98 \\
\hline Random Effects & Variance & $\mathrm{SD}$ & \\
\hline Chapter & 231.94 & 15.23 & \\
\hline Book & 83.22 & 9.12 & \\
\hline Residual & 159.64 & 12.64 & \\
\hline
\end{tabular}


Table 5. Linear mixed models investigating differences in positivity in different Biblical translations.

\begin{tabular}{|c|c|c|c|}
\hline Factor & $\mathrm{B}$ & SE & $\mathbf{t}$ \\
\hline Intercept (NIV and OT Baseline) & 12.96 & 1.24 & 10.48 \\
\hline NASB & -1.10 & 0.64 & -1.71 \\
\hline ESV & -2.21 & 0.64 & -3.45 \\
\hline KJV & 0.17 & 0.64 & 0.26 \\
\hline NKJV & 0.57 & 0.64 & 0.89 \\
\hline HCSB & 0.20 & 0.64 & 0.31 \\
\hline NRSV-CE & -1.03 & 0.64 & -1.61 \\
\hline GNT & -0.45 & 0.64 & -0.70 \\
\hline NIRV & 2.14 & 0.64 & 3.34 \\
\hline NLT & 2.82 & 0.64 & 4.39 \\
\hline Message & 4.00 & 0.64 & 6.24 \\
\hline Testament (OT baseline) & -8.36 & 1.44 & -5.80 \\
\hline NASB*Testament & 0.03 & 0.73 & 0.04 \\
\hline ESV*Testament & 0.83 & 0.73 & 1.15 \\
\hline KJV*Testament & 0.43 & 0.73 & 0.59 \\
\hline NKJV*Testament & -0.18 & 0.73 & -0.25 \\
\hline HCSB*Testament & -0.23 & 0.73 & -0.31 \\
\hline NRSV-CE*Testament & 0.50 & 0.73 & 0.68 \\
\hline GNT*Testament & 0.45 & 0.73 & 0.62 \\
\hline NIRV*Testament & 0.83 & 0.73 & 1.15 \\
\hline NLT*Testament & -1.12 & 0.73 & -1.54 \\
\hline Message*Testament & -2.27 & 0.73 & -3.13 \\
\hline Random Effects & Variance & SD & \\
\hline Chapter & 26.86 & 5.18 & \\
\hline Book & 28.28 & 5.32 & \\
\hline Residual & 53.45 & 7.31 & \\
\hline
\end{tabular}


Figure 1. Mean levels of positivity in the Old and New Testament for different Bible translations.

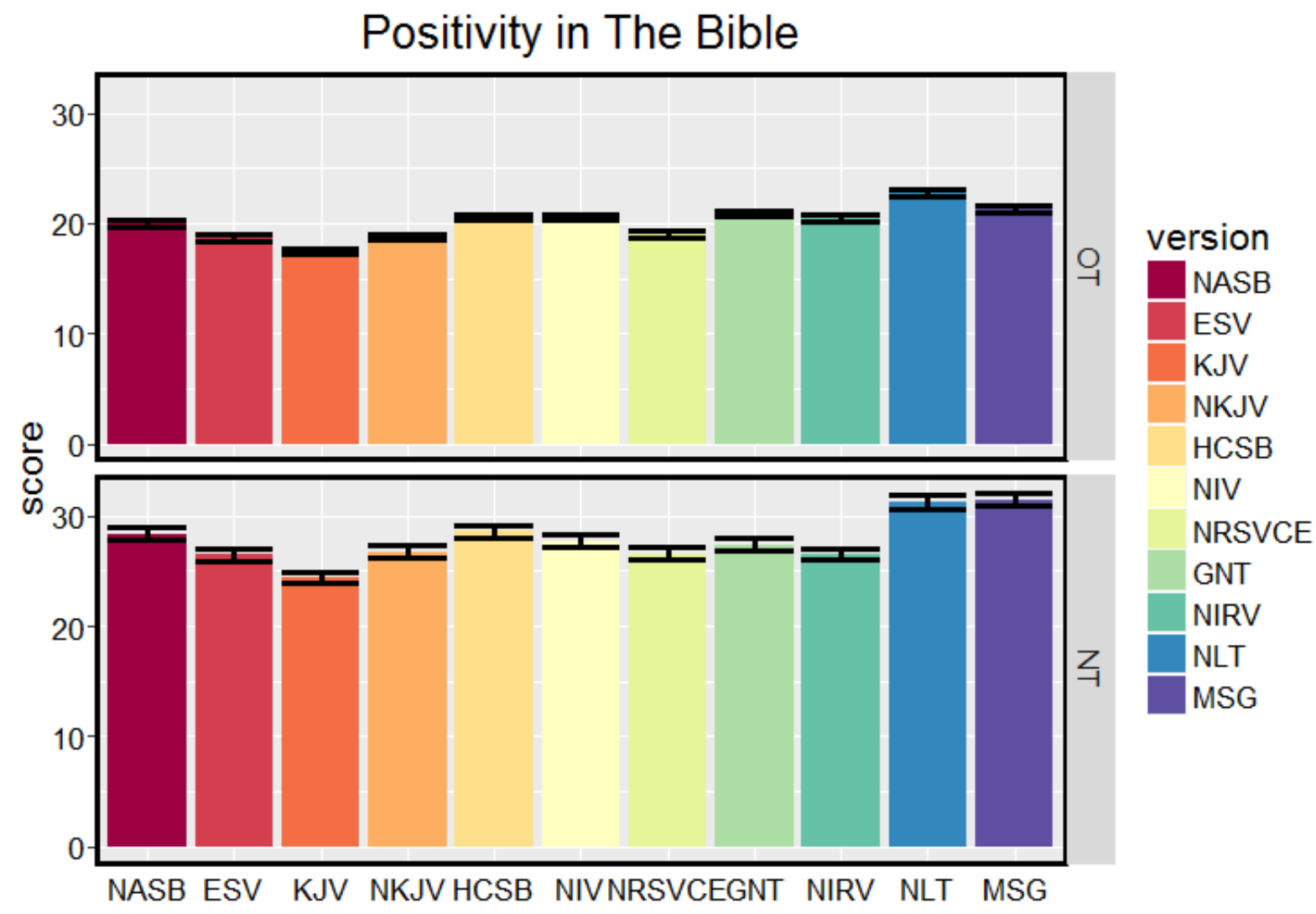


Figure 2.

Mean levels of negativity present in different Bible translations.

Negativity in The Bible

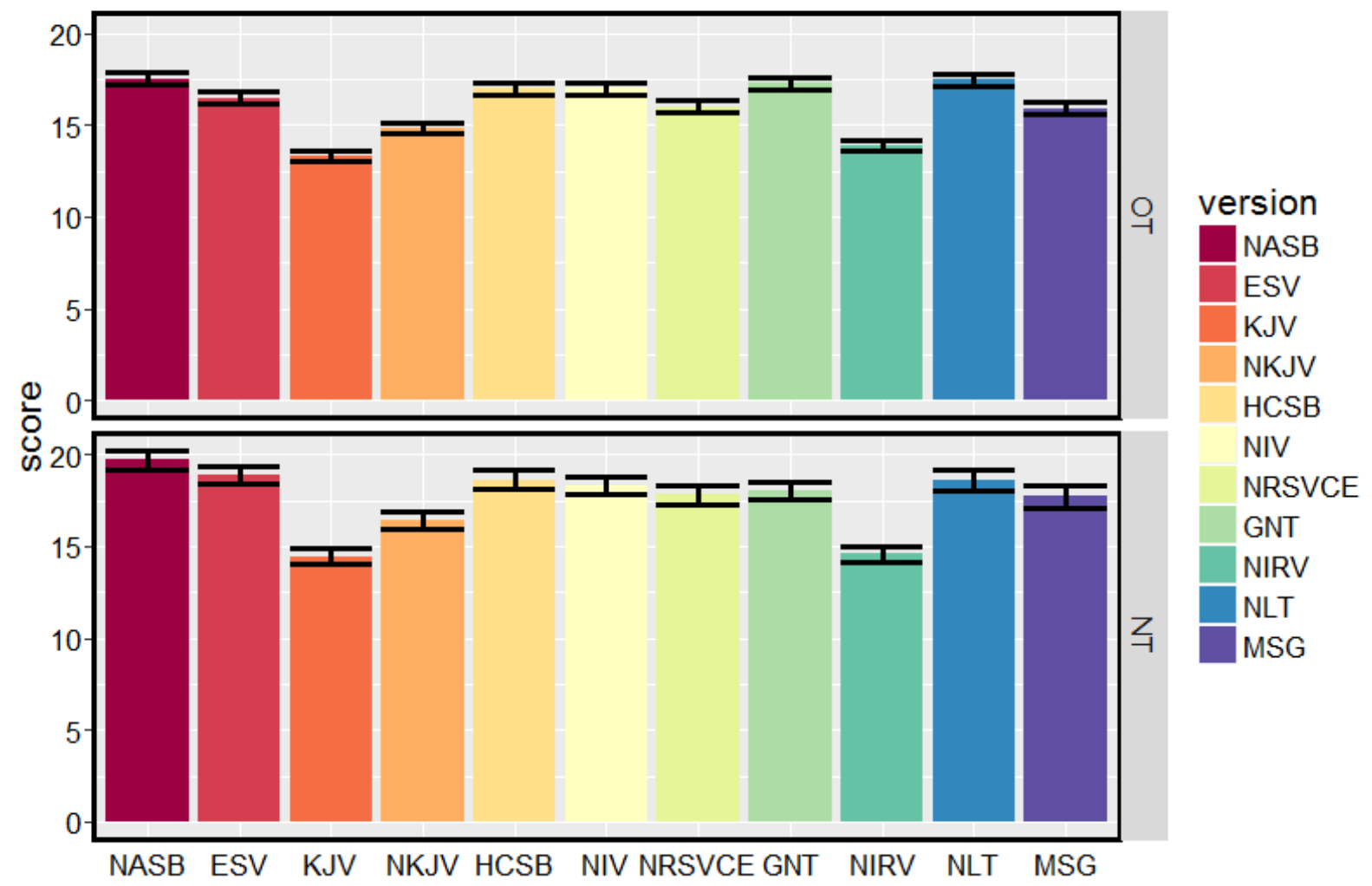


Figure 3. Mean levels of emotionality present in different Bible translations.

\section{Emotionality in The Bible}

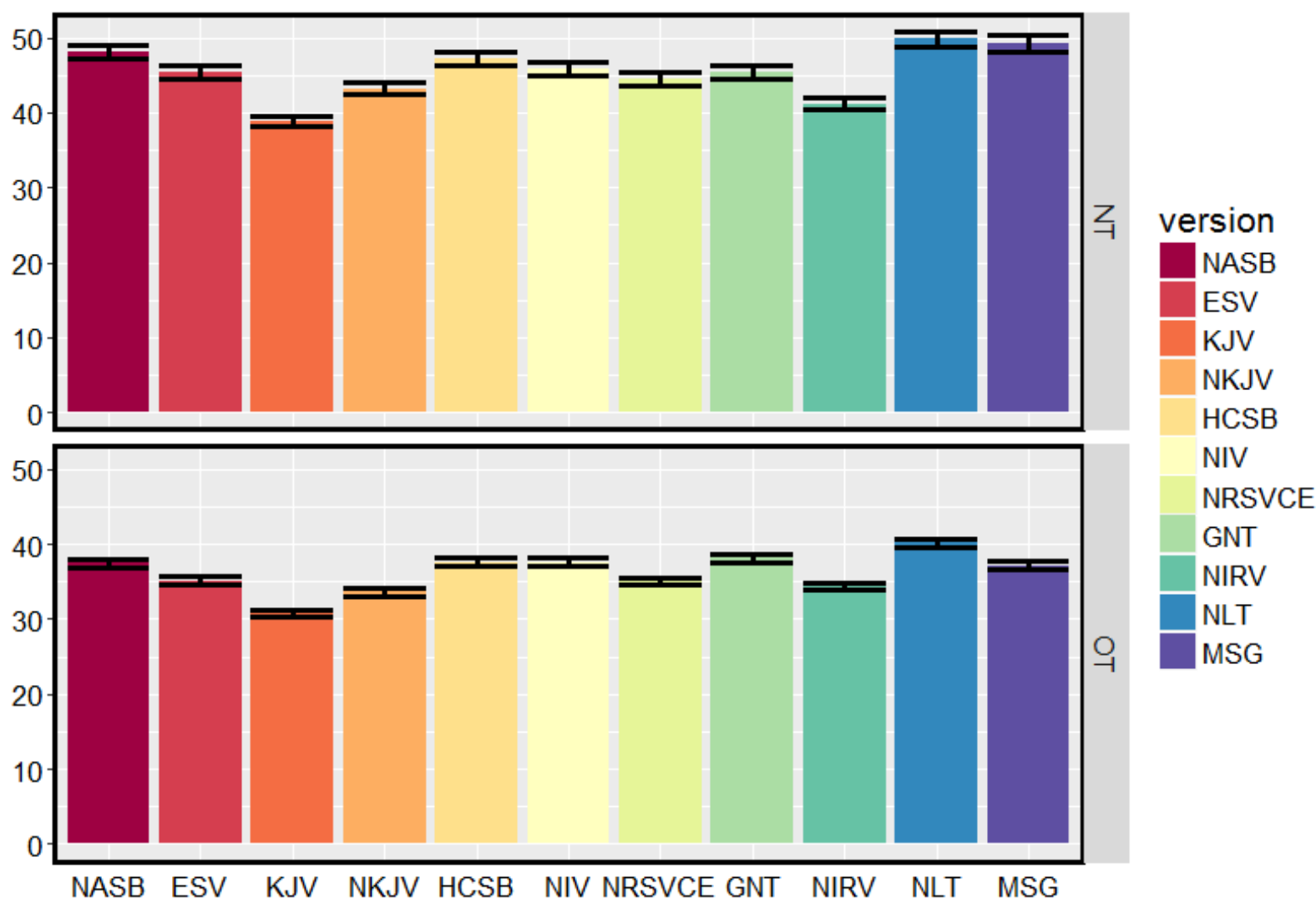


Figure 4. Valence scored as positivity minus negativity in different Bible translations.

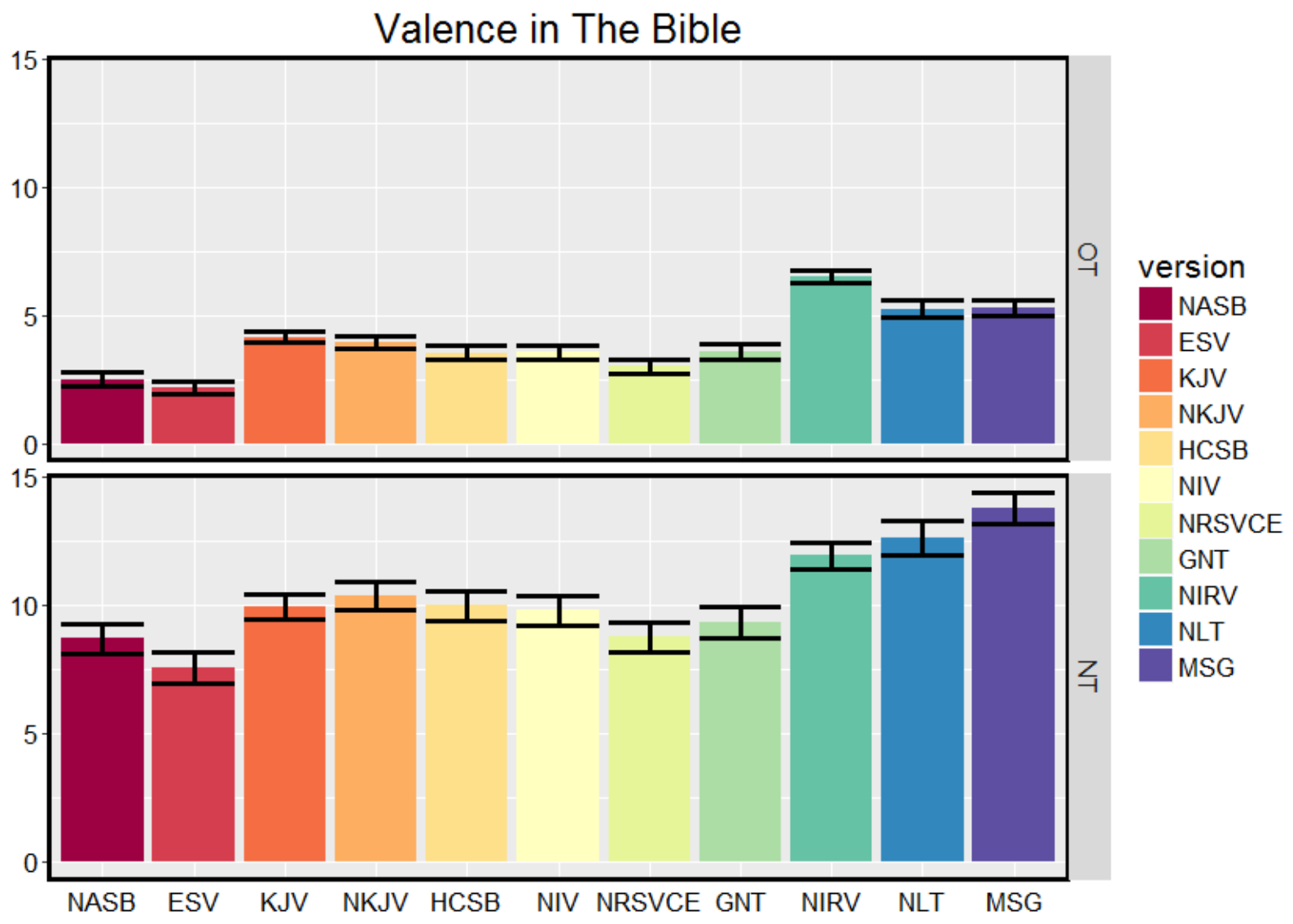

